\title{
Breaking the Stereotypes: Analysis and Prevention of Criminal Misjudged Cases in the Procedure of Criminal Trial from the Perspective of Evidentiary Adjudication
}

\author{
Min $\mathrm{CHEN}^{1 \mathrm{a}}$, Dao-Yong TU $\mathrm{TU}^{2 \mathrm{~b}}$ \\ ${ }^{1}$ School of Humanities \& Foreign Language, Xi'an University of Technology, Xi'an, China; \\ ${ }^{1}$ Law School, Wu Han University, Wu Han, China \\ Distinct addresses: 58 Yan Xiang Road, Shaanxi Xi'an 710054, China \\ ${ }^{2}$ Third Civil Tribunal, Higher Court of Shaanxi Province, Xi'an, Shaanxi province \\ Distinct addresses: 58 Yan Xiang Road, Shaanxi Xi'an 710054, China \\ aemail:marcy666 @163.com, bemail:1725743175@qq.com \\ *Corresponding author: Min CHEN
}

Keywords: evidentiary adjudication; misjudged criminal cases; criminal trial

\begin{abstract}
Effective prevention of misjudged criminal cases has become a consensus of almost all countries in their respective national criminal procedure legislation and judicial practice, and people are increasingly aware that the major stereotype or crux of misjudged criminal cases lies in the evidences collected. At the stage of criminal trial, major causes resulting in misjudged cases are that the principle of exclusion of illegal evidence is neglected and standard of legal evidence is breached. All these problems are directly and indirectly in violation of the principle of evidentiary adjudication. To rectify misjudged criminal cases we should try to discover their inherent generation mechanism and further find out effective solutions rather than ridiculously relying on "Return of the Dead" or "the murderer's showing up".
\end{abstract}

\section{Introduction}

People are increasingly aware that the major stereotype or crux of misjudged criminal cases lies in the evidences collected. However, it is no easy to thoroughly analyze and find out effective solution to these problems. To thoroughly analyze these problems in the horizon of jurisprudence, the author argues that we should focus on the key provisions of Evidence Act-how these provisions are implemented in criminal trials and whether or not the related institutions and regulations are fully developed. Accordingly, the author tries to put forth a sound way for judges to prevent criminal cases from being misjudged in their judicial practice.

\section{How Evidence-Related Misjudged Criminal Cases at the Stage of Criminal Trials}

\section{Shackles of Judicial Trials —_Difficulties in Excluding Illegal Evidence}

Major causes resulting in misjudged cases at the stage of criminal trials are that the principle of exclusion of illegal evidence is neglected and standard of legal evidence is breached. In judicial practice, it is rather difficult to exclude illegal expert opinions, notes and audio-visual recordings, and how to exclude those illegal evidences is a much disputed issue. Though the no-torture certification materials for evidence collection provided by the investigative organizations have no match in probative force to the investigators' appearance in court as witness, such practice is still quite in fashion. Our country's Criminal Procedural Law provides that it is required that the defendant who applies for excluding illegal evidences shall supply relevant clues and materials. Consequently, the defendant complains now and then that it is difficult to collect some evidence or some evidence collection is faulty. 


\section{Awkwardness of Court Certification___Alienation of Standards of Testification}

Article 53 of the Criminal Procedural Law (2012) outlines the conditions under which conviction and measurement of penalty are specified based on true and sufficient evidences. It requires that all evidences are integrated and no illegal or doubtful evidences are included. Exclusion of doubtful evidences aims at preventing innocent citizens from being convicted as guilty, and so this principle is the key to avoid a case from being obviously misjudged. The court should holds that evidences which are not testified or insufficient be excluded. In judicial practice, we should be careful about two types of alienation: one is that the evidences are generally true and sufficient but not true and sufficient enough and the other is that doubtful crime ought to be convicted a lighter punishment instead of seeking further legal and true evidences.

\section{Cut through Dense Fogs: Evidence Analysis at the Stage of Criminal Trials to Prevent a Case from Being Misjudged}

That a case is convicted beyond doubt is just a utopia. To rectify misjudged cases we should normalize, systemize and realize the prevention of misjudged cases depending upon the principle of evidentiary adjudication and related institutions and regulations, instead of ridiculously relying on "Return of the Dead" or "the murderer's showing up".

\section{Breaking the Shackles - Scientific Stipulation on Exclusion of Illegal Evidence}

Prevention of misjudged cases is closely related to the patterns suitable to the principle of exclusion of illegal evidences. There are two such patterns nowadays: one is thorough exclusion of illegal evidences, the other is relative exclusion of illegal evidences. Which pattern to select manifests a country's purpose of criminal proceedings and its guideline in the prevention of misjudged criminal cases. Though many exceptions are outlined, the US adopts the thorough pattern, whereas Japan and Germany adopt the relative pattern. To make breakthrough in preventing misjudged criminal cases, our country ought to adopt the thorough pattern. As to puzzles mentioned above, the author tries to put forth four ways to excluding illegal evidences as follows. (1) Normalize exclusionary rules in respect of illegal expert opinions, illegal notes and illegal audio-visual recordings, and lower the requirement to the application for excluding illegal evidences and lay strict requirements on the legality of evidences the public prosecutors provide. (2)Endow the counsel of the accused with right of presence to deal with the difficulty in starting a program of illegal evidence exclusion. Article 356 of Italy's Code of Criminal Procedure provides that the accused shall not be interrogated unless his counsel is on the scene; otherwise, any presentation of the accused is invalid. In the US, the accused has the right of asking his counsel to be on the scene. To endow the counsel of the accused with presence right is a guarantee to carrying out exclusionary rules and a practical way to solve the difficulty in excluding illegal evidences. On the basis of our national conditions and by referring to other countries' experiences, the author thinks that a solution may be designed as follows: Outline the exact types of cases in which the counsel may be on the scene when the accused is interrogated as it is not practical in China for the counsel's presence at all cases when the accused is interrogated, i.e. the counsel may be on the scene when the accused as to grave crime cases is interrogated; Define the responsibilities and obligations of the counsel on the scene and endow the counsel with certain power to exclude illegal evidences, e.g. only the notes which are signed by the counsel can be taken as legal evidences. (3)Negate the certification materials of case investigation provided by the investigative organizations and require that the investigators appear in court. The Two Rules of Evidence provide that the prosecutor should supply the court with officially sealed certification materials to prove that the evidences collected are not illegal. Article 101 of the Judicial Interpretation of the Criminal Procedural Law (2013) provides that the certification materials of case investigation shall be officially sealed and also be signed by the investigators and such materials alone cannot be used to prove that the evidences collected are not illegal. Such provisions with Chinese characteristics aim at strengthening the probative force of the certification materials of case investigation, but exert 
negative influence upon the implementation of the principle of direct and verbal trial in excluding illegal evidences. (4) Perfect exclusionary rules of documentary evidences, physical evidences. Based on the evidence collection pattern of judicial authorities, coercive measures ought to be attached to exclusionary rules so as to come closer to the pattern of thorough exclusion of illegal evidences. For the purpose of thoroughly preventing criminal cases for being misjudged, all illegal documentary evidences and illegal physical evidences ought to be excluded.

\section{Create Practical Methodology_ Exclusion of Reasonable Doubts}

Exclusion of Reasonable Doubts as a specimen of inspecting the transplantation of observation of legal transplants samples has been paying off in our country. However, institutions and regulations as to such transplantation are quite problematic, so are the judicial personnel's deciphering and applications of such transplanted laws, making up root causes resulting in misjudged criminal cases. Though Exclusion of Reasonable Doubts is integrated into the standards of evidentiary adjudication, it should better be used by the judges as a proof method to find out a unified and effective path to criminal adjudication in order that criminal cases be prevented from being misjudged in judicial practice. Exclusion of Reasonable Doubts adopted as a proof method should be specified as contradiction elimination method or doubts elimination method based on effective and legal evidences relevant to the case. Firstly, all contradictions and doubts as to the case ought to be clarified in order to find out the fundamental contradictions in order to decide whether or not the accused is guilty, and non-fundamental contradictions to decide whether or not the accused is to shoulder and how to shoulder any criminal liability or responsibility. Secondly, the judges should try to decipher and testify these contradictions in accordance with such classified order. This is indeed the process of deciphering and solving contractions and also the process of excluding possible doubts. Only the doubts which may overthrow so-called ascertained primary facts can be taken as reasonable doubts. In such process, the judges may testify whether or not certain doubts are reasonable through applying the rule of experience (i.e. the rule of thumb, in which the experience refers to the experience of universality and able to be verified) by which the judges will make sure whether or not some doubts may be reasonably dismissed or excluded and the rule of logic by which the judges will identify facts by following the law of logical reasoning. When Exclusion of Reasonable Doubts used as proof method in practice, the principle of direct and verbal trial should also be fully implemented to examine evidences of direct language and thus the judges will decide whether or not those evidences are sound enough in reference to the method of direct examination and cross-examination in the common law system. The centrism of solely relaying on dossier and written testimony in our country should be totally abandoned. If the witness' not appearing in court does not prevent the written testimony from being used by the accuser and adopted by the court, it will be difficult to decide the authenticity of the evidences and it will be possible for the case to be misjudged. The judges' determination to exclude reasonable doubts is based on law. In the amendment to Criminal Procedural Law, so-called scientific evidences without the support of direct language testimony are thoroughly excluded but common written testimony is not further regulated. Consequently, the author holds that to controversial evidences as to capital felony the principle of direct and verbal trial should be enforced in order shatter the harsh fort of evidences built by the accuser without witness' appearance in court. After application of all above mentioned means and methods, if fundamental contradictions cannot be proved as reasonable doubts and non-fundamental contradictions are not to be deciphered and examined, then there might be open a slip in preventing a case from being misjudged. By combining with the evidence pattern of our country, the judges should fully apply the principle of exclusion of reasonable doubts in all evidences collected for the purpose of better preventing criminal cases from being misjudged.

\section{Conclusion}

As the phenomenon of misjudged criminal cases is common for a country in the process of governance by law instead of a country-specific or times-specific phenomenon, we hope that the judicial justice will be achieved for a country in its process of orderly judicial reform in 
readdressing misjudged criminal cases. The author maintains that at the stage of criminal trials, the thorough pattern of exclusion reasonable doubts or the relative pattern of exclusion reasonable doubts should be adopted in order that illegal evidences will be excluded to prevent criminal cases from be misjudged on the one hand, and on the other hand, exclusion of reasonable doubts should be adopted by the judges as a proof method which may be embodied as contradiction exclusion method or doubts exclusion method, in order to effectively prevent a criminal case from being misjudged in judicial practice.

\section{Acknowledgment}

Foundation item: Xi'an University of Technology Fund Project (No. 109-211301) and Education Department of Shaanxi Provincial Government (No. 13JK0085)

\section{References:}

1. [Germany] Weigend, Thomas. Criminal Procedural Law in Germany[M]. Translated by Yue Liling \& Wen Xixoajie. Yue Liling. The Publishing House of China University of Political Science \& Law. 2004: p226.

2. He Jiahong \& Liu Pinxin. The Law of Evidence[M]. Law Press. 2011: p114.

3. [US] Garrett, Brandon L.. Convicting The Innocent: Where Criminal Prosecutions Go Wrong.[M]. Translated by Li Fenfei. The Publishing House of China University of Political Science \& Law. 2015: p75.

4. Lin Xifen. Three Breakthroughs and Five Insufficiencies of the Two Rules of Evidence. [J]. Modern Law Science. 2011(2): p175. 